\title{
Soroprevalência e fatores de risco para a língua azul em carneiros das mesorregiões do Sertão e da Borborema, semi-árido do Estado da Paraíba, Brasil
}

\author{
Seroprevalence and risk factors for Bluetongue in rams of the Sertão and Borborema mesoregions, \\ semi-arid of Paraíba state, Northeastern Brazil
}

\author{
Francisco de Assis Leandro Alves ${ }^{I}$ Clebert José Alves ${ }^{I^{*}}$ Sérgio Santos de Azevedo ${ }^{\mathrm{I}}$ \\ Wilson Wolflan Silva' ${ }^{I}$ Maria Luana Cristyni Rodrigues Silva ${ }^{I}$ Zélia Inês Portela Lobato ${ }^{\text {II }}$ \\ Inácio José Clementino ${ }^{\text {III }}$
}

\section{RESUMO}

Neste estudo foi determinada a prevalência de anticorpos contra o vírus da língua azul em carneiros das mesorregiões do Sertão e da Borborema, semi-árido do Estado da Paraíba, bem como foram identificados os fatores de risco associados à infecção. A amostragem foi delineada para a determinação da prevalência de propriedades positivas (focos) $e$ de animais soropositivos por mesorregião. Foi realizada uma seleção aleatória de unidades primárias, composta por 189 propriedades no Sertão e 100 propriedades na Borborema. Dentro das unidades primárias, foram amostrados todos os carneiros (unidades secundárias), resultando em 321 animais no Sertão e 185 na Borborema. Na ocasião da coleta, foi aplicado um questionário epidemiológico por propriedade. Para o diagnóstico sorológico, foi utilizada a prova de imunodifusão em gel de ágar (IDGA), com antígeno produzido na Escola de Veterinária da Universidade Federal de Minas Gerais). Uma propriedade foi considerada foco quando apresentou pelo menos um animal soropositivo. Na mesorregião do Sertão, as prevalências de focos e de animais soropositivos foram de $11,6 \%$ [7,8\% - 17,1\%] e 8,4\% [5,7\% - 12,3\%], respectivamente. Na mesorregião da Borborema, a prevalência de focos foi de $0,0 \%$ [0,0\% - 3,6\%] e a prevalência de animais soropositivos foi de 0,0\% [0,0\% - 2,0\%]. Os fatores de risco associados à língua azul foram a não realização de higiene das instalações $(O R=5,51)$ e a vermifugação dos animais duas a quatro vezes ao ano $(O R=4,44)$.

Palavras-chave: língua azul, soroprevalência, fatores de risco, carneiros, Estado da Paraíba.

\section{ABSTRACT}

The prevalence of antibodies against Bluetongue virus in rams of the Sertão and Borborema mesoregions, semi- arid of the Paraíba state, Northeastern Brazil, was determined, and risk factors for the infection were identified. The sampling was delineated for the determination of the prevalence of positive herds and seropositive animals for each mesoregion. Herds (primary units) were randomly selected in the Sertão mesoregion $(n=189)$ and in the Borborema mesoregion $(n=$ 100). Within the primary units, all rams (secondary units) were sampled, resulting in 321 animals of the Sertão mesoregion and in 185 animals of the Borborema mesoregion. During collection, an epidemiological questionnaire was applied to each herd. For serological diagnosis, the agar gel immunodiffusion test (AGID) with antigen produced in the School of Veterinary Medicine of the Federal University of Minas Gerais was carried out. Herds with at least one positive animal were considered positive. In Sertão mesoregion, the prevalence of positive herds and seropositive animals were $11.6 \%$ [7.8\% $17.1 \%]$ and $8.4 \%$ [5.7\% - 12.3\%], respectively. In Borborema mesoregion, the prevalence of positive herds was $0.0 \%[0.0 \%$ - 3.6\%] and the prevalence of seropositive animals was $0.0 \%$ [0.0\% - 2.0\%]. The risk factors associated with Bluetongue were lack of cleaning and disinfection of facilities $(O R=5.51)$, and administration of anti-parasitic treatment twice to four times per year $(O R=4.44)$.

Key words: Bluetongue, seroprevalence, risk factors, rams, Paraíba state.

\section{INTRODUÇAO}

A língua azul (LA) é uma doença viral, transmitida por vetores hematófagos do gênero Culicoides sp., que afeta todos os ruminantes

'Unidade Acadêmica de Medicina Veterinária (UAMV), Centro de Saúde e Tecnologia Rural (CSTR), Universidade Federal de Campina Grande (UFCG). Av. Universitária, s/n, Bairro Santa Cecília, CP 64, 58700-970, Patos, PB, Brasil. E-mail: clebertja@uol.com.br. *Autor para correspondência.

IIEscola de Veterinária, Universidade Federal de Minas Gerais (UFMG), Belo Horizonte, MG, Brasil.

IIITécnico da Secretaria do Desenvolvimento da Agropecuária e da Pesca da Paraíba, João Pessoa, PB, Brasil. 
domésticos e selvagens, contudo, a ocorrência da doença clínica tem sido demonstrada principalmente em ovinos (PARSONSON, 1992). A primeira indicação da presença do vírus da língua azul (VLA) no Brasil foi relatada por SILVA (1978), que demonstrou a presença de anticorpos em bovinos e em ovinos de propriedades do Estado de São Paulo. A partir daí, vários inquéritos sorológicos realizados no Brasil, em bovinos, caprinos, ovinos e bubalinos, pela prova de imunodifusão em gel de ágar (IDGA), indicaram que o vírus está amplamente distribuído em todas as regiões testadas (LOBATO, 1999; LAENDER, 2002).

A população ovina do Brasil é de cerca de 16 milhões de cabeças, das quais 58\% estão localizadas na região Nordeste (BRASIL, 2006). No Estado da Paraíba, há 414.800 cabeças e de acordo com o último Censo Agropecuário, realizado em 1996, existem 251.312 ovelhas, 21.980 carneiros reprodutores e 129.529 animais com menos de um ano de idade, estando esse plantel distribuído em 20.518 propriedades criadoras, com uma média de 22 animais por propriedade.

As perdas econômicas causadas pela LA se devem às restrições na importação e na exportação de animais e de seu material genético e aos transtornos reprodutivos associados à infecção (COSTA et al., 2006). Além disso, a importância e a complexidade do papel do gado bovino como reservatório, o contínuo surgimento de focos de infecção e/ou da doença em diversos países e a contaminação de produtos biológicos dificultam o comércio destes produtos nos países do Mercosul, nos Estados Unidos da América e na Europa.

Considerando a importância da ovinocultura para o Nordeste do Brasil, em especial no Estado da Paraíba, o presente trabalho teve como objetivos determinar a prevalência de anticorpos contra o vírus da LA em carneiros procedentes de propriedades das mesorregiões do Sertão e da Borborema, Estado da Paraíba e identificar fatores de risco associados à infecção.

\section{MATERIAL E MÉTODOS}

Tamanho da amostra

A amostragem foi delineada para a determinação da prevalência de propriedades positivas (focos) e de animais soropositivos por mesorregião. $\mathrm{O}$ número de propriedades (unidades primárias) a serem amostradas foi calculado com o programa EpiInfo, versão 6.04 (DEAN, 1994), com o emprego dos seguintes parâmetros: (a) prevalência esperada de 50\% (valor adotado para maximizar a amostra); (b) nível de confiança de 95\%; e (c) erro absoluto de $10 \%$ (THRUSFIELD, 1995). Para as mesorregiões do Sertão Paraibano e da Borborema, que apresentam 7.087 e 6.664 propriedades criadoras de ovinos, respectivamente, a amostra foi de 95 propriedades em cada mesorregião. Por motivo de segurança, foram visitadas 189 propriedades na mesorregião do Sertão Paraibano e 100 na mesorregião da Borborema, no período de janeiro a agosto de 2004. A técnica de amostragem utilizada para o sorteio das propriedades foi a sistemática aleatória (THRUSFIELD, 1995), na qual a seleção das propriedades foi feita em intervalos iguais, sendo a primeira selecionada ao acaso dentro da fração amostral (número total de propriedades/número de propriedades a serem amostradas). Foi utilizado, como quadro amostral, o cadastro de propriedades da EMATER-PB e de associações de criadores de ovinos do Estado da Paraíba. Dentro das unidades primárias, foram amostrados todos os carneiros (unidades secundárias), resultando em 321 animais no Sertão e 185 na Borborema. O sangue dos ovinos foi coletado por venopunção jugular, sendo utilizados tubos a vácuo.

Diagnóstico sorológico

Os soros foram testados pela prova de imunodifusão em gel de ágar (IDGA), segundo COSTA (2000), utilizando antígeno produzido na Escola de Medicina Veterinária da Universidade Federal de Minas Gerais (UFMG) (VLA -4). Um soro foi considerado positivo quando houve a formação da linha de precipitação entre o antígeno e o soro teste e da linha de identidade entre o soro teste e o soro controle positivo.

Prevalência de propriedades positivas (focos)

$\mathrm{O}$ cálculo da prevalência de propriedades positivas (focos) nas duas mesorregiões foi feito de forma ponderada, considerando os seguintes parâmetros: condição da propriedade (positiva ou negativa), mesorregião da propriedade e o peso 
estatístico. Para o cálculo da prevalência de focos em cada mesorregião, considerou-se uma amostra aleatória simples, utilizando-se como parâmetro o número de focos e de propriedades amostradas na mesorregião, sendo que foi considerada foco a propriedade que tinha pelo menos um animal positivo. Utilizou-se o programa SPSS for Windows, versão 13.0, para a realização de todos os cálculos.

Prevalência de animais soropositivos para a LA

Para o cálculo da prevalência dos animais soropositivos para a LA nas duas mesorregiões também foi realizada uma ponderação. Os parâmetros utilizados para os cálculos foram a condição do animal (positivo ou negativo), a mesorregião do animal, o número de identificação da propriedade e o peso estatístico de cada animal. Os cálculos das prevalências de animais soropositivos foram feitos com o programa SPSS for Windows, versão 13.0. Para a comparação entre as prevalências de propriedades positivas e animais soropositivos nas duas mesorregiões, foi utilizado o teste de qui-quadrado (ZAR, 1999).

Análise de fatores de risco para a LA

Para a análise de possíveis fatores de risco associados à condição de foco, foram utilizados os dados obtidos por meio dos questionários epidemiológicos aplicados nas propriedades. Foi realizada em duas etapas: análise univariada e análise multivariada. Na análise univariada, cada variável independente foi cruzada com a variável dependente (condição sanitária da propriedade). As que apresentaram um valor de $\mathrm{P} \leq 0,2$ pelo teste de quiquadrado $(Z A R, 1999)$ foram selecionadas e oferecidas para a análise multivariada, utilizando-se a regressão logística múltipla (HOSMER \& LEMESHOW, 2000), para a definição de um modelo que melhor identificasse os fatores de risco. O nível de significância adotado na análise múltipla foi de 5\%. O ajuste do modelo final foi verificado com o teste de Hosmer e Lemeshow, no qual um $\mathrm{P} \geq 0,05$ indica que o modelo está ajustado. A colinearidade entre as variáveis preditoras foi verificada por meio da análise de correlação e, para aquelas que apresentaram forte colinearidade (coeficiente de correlação $\geq 0,9$ ), uma das duas foi excluída da análise múltipla de acordo com a plausibilidade biológica (DOHOO et al., 1996). As análises foram realizadas com o programa SPSS for Windows, versão 13.0.

\section{RESULTADOS E DISCUSSÃO}

No presente trabalho, observou-se uma prevalência de $11,6 \%[7,8 \%$ - 17,1\%] de propriedades com ovinos positivos e $8,4 \%[5,7 \%-12,3 \%]$ de animais soropositivos na mesorregião do Sertão. Na mesorregião da Borborema, não foram encontrados animais soropositivos, contudo, nesta área, a presença do mosquito transmissor já foi confirmada (ARAÚJOLIMA et al., 2004). No Sudoeste e Sudeste do Estado do Rio Grande do Sul, COSTA et al. (2006) examinaram 1341 ovinos e encontraram $0,74 \%$ de propriedades positivas e $0,15 \%$ de animais soropositivos, valores estes muito inferiores aos encontrados no presente trabalho, o que pode ser justificado pelas condições climáticas adversas à multiplicação e à atividade do vetor naquelas regiões.

As prevalências de focos e de animais soropositivos para a LA nas microrregiões Sertão e Borborema do Estado da Paraíba são apresentadas nas tabelas 1 e 2 . Houve diferenças significativas entre as duas mesorregiões com relação às prevalências de focos $(\mathrm{P}=0,0001)$ e de animais soropositivos $(\mathrm{P}=0,0001)$ pelo teste de qui-quadrado.

As propriedades onde foi evidenciada a presença de animais soropositivos apresentavam uma

Tabela 1 - Prevalência de propriedades positivas para LA em carneiros e respectivo intervalo de confiança de 95\% (IC 95\%) nas mesorregiões do Sertão e da Borborema, Estado da Paraíba, Brasil.

\begin{tabular}{lccccc}
\hline Mesorregião & № total de propriedades & $\begin{array}{c}\text { № de propriedades } \\
\text { amostradas }\end{array}$ & № de focos & $\begin{array}{c}\text { Prevalência } \\
(\%)\end{array}$ & IC 95\% (\%) \\
\hline Sertão & 7.078 & 189 & 22 & 11,6 & {$[7,8-17,1]$} \\
Borborema & 6.664 & 100 & 0 & 0,0 & {$[0,0-3,6]$} \\
Total & 13.751 & 289 & 22 & 6,0 & {$[4,0-8,9]$} \\
\hline
\end{tabular}


Tabela 2 - Prevalência de carneiros soropositivos para LA e respectivos intervalos de confiança de 95\% (IC 95\%) nas mesorregiões do Sertão e da Borborema, Estado da Paraíba, Brasil.

\begin{tabular}{|c|c|c|c|c|c|}
\hline Mesorregião & № total de ovinos & $\begin{array}{l}\text { № de ovinos } \\
\text { amostrados }\end{array}$ & $\begin{array}{c}\text { № de ovinos } \\
\text { positivos }\end{array}$ & Prevalência (\%) & IC $95 \%(\%)$ \\
\hline Sertão & 159.149 & 321 & 27 & 8,4 & {$[5,7-12,3]$} \\
\hline Borborema & 190.201 & 185 & 0 & 0 & {$[0,0-2,0]$} \\
\hline Total & 349.350 & 506 & 27 & 4,1 & {$[2,7-6,0]$} \\
\hline
\end{tabular}

criação intensiva, reforçando a citação de COSTA (2000), que se refere às criações de animais de maneira intensiva ou estabulada como as que apresentam uma maior susceptibilidade ao vetor transmissor do vírus. Em tais propriedades, a atividade agrícola predominantemente mecanizada e irrigada duas vezes ao dia cria um microclima favorável à sobrevivência do vetor; ressalte-se, ainda, que esta mesorregião é cortada por um rio perene e é marcada por manejos para a conservação de água o ano todo, como barragens subterrâneas, pequenos açudes e lacustres.

Na mesorregião do Sertão paraibano, na qual foram encontrados animais soropositivos, o hábito da caça é rotineiro entre os agricultores, principalmente a caça de tatus (Dasypus novemcinctus). Estes animais, depois de capturados, são criados em ambientes domiciliares, criando, assim, um possível elo de transmissão, uma vez que estes animais são considerados reservatórios do vírus da LA (OSBURN, 1994). A distância entre as duas propriedades onde foi verificada a existência de animais reagentes é de aproximadamente $8 \mathrm{~km}$. Além disso, são criados, no mesmo microclima, bovinos de raças mistas com aptidão leiteira, levando a crer que pode haver também a presença de bovinos soro reagentes para LA. Por conseguinte, várias espécies de culicóides de comprovada competência na transmissão da doença se alimentam preferencialmente de bovinos. Devido a este fator e a uma prolongada viremia (SELLERS, 1981), os bovinos podem funcionar como reservatórios durante o período menos quente, em que o número de vetores é menor (GIBBS \& GREINNER, 1988). LUEDKE \& ANAKWENZE (1972) citam a importância da criação de caprinos e ovinos e a presença de Culicoides sp. numa mesma área. Neste trabalho, em todas as propriedades que apresentaram animais reagentes, além de ovinos, alguns produtores criavam caprinos e bovinos e outros somente caprinos, sugerindo que estes animais podem servir de fontes de infecção.
Os resultados da análise univariada com as variáveis mais associadas com a presença da doença, na mesorregião do Sertão paraibano, são apresentados na tabela 3. Os fatores de risco para a LA na mesorregião do Sertão paraibano, determinados por regressão logística múltipla, são apresentados na tabela 4 . O modelo final mostrou que propriedades nas quais não é realizada a higiene nas instalações e a vermifugação dos animais é feita na periodicidade de duas a quatro vezes ao ano possuem maior chance de serem focos de LA. O modelo final apresentou um bom ajuste de acordo com o teste de Hosmer e Lemeshow $\left(\chi^{2}=1,07\right.$; $\mathrm{P}=0,78)$.

A não realização da higiene das instalações como fator de risco já era esperado, pois este fator pode contribuir para a proliferação de vetores transmissores da doença. $\mathrm{O}$ risco de disseminação da LA, de acordo com a freqüência de vermifugação, também apontada como fator de risco no presente trabalho, apresenta plausibilidade biológica, uma vez que as aglomerações de animais, bem como o possível uso comum de seringas ou aplicadores orais na ocasião da vermifugação, podem contribuir para a disseminação do agente nos rebanhos.

A inexistência de dados relativos aos sorotipos do vírus da LA existentes no Brasil e a sua distribuição nos diferentes Estados dificultam o controle e a adoção de medidas que evitem a introdução de novos sorotipos no país ou em áreas específicas. Os resultados obtidos na presente pesquisa apontam uma prevalência alta de animais soropositivos para a LA e de propriedades com animais soropositivos na mesorregião do Sertão do Estado da Paraíba. Esses dados levantam preocupações devido à importância econômica da doença e ao fato de ser uma doença de notificação obrigatória, sendo sua ocorrência um evento negativo para o comércio de animais e subprodutos de origem animal.

Ciência Rural, v.39, n.2, mar-abr, 2009. 
Tabela 3 - Distribuição de propriedades positivas (focos) e negativas para LA em carneiros da mesorregião do Sertão, Estado da Paraíba, segundo os possíveis fatores de risco e a probabilidade de ocorrência ao acaso $(\mathrm{P})$ na análise univariada.

\begin{tabular}{|c|c|c|c|c|c|}
\hline \multirow{3}{*}{ Variáveis } & \multicolumn{4}{|c|}{ 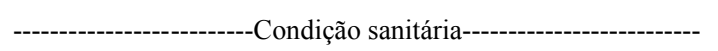 } & \multirow{3}{*}{$\mathrm{P}$} \\
\hline & \multicolumn{2}{|c|}{----------Positiva---------- } & \multicolumn{2}{|c|}{----------Negativa---------- } & \\
\hline & $\mathrm{N}$ & $\%$ & $\mathrm{~N}$ & $\%$ & \\
\hline \multicolumn{6}{|l|}{ Tipo de exploração } \\
\hline Cria/Recria/Engorda & $5 / 75$ & 6,7 & $70 / 75$ & 93,3 & \multirow{3}{*}{$0,110^{*}$} \\
\hline Reprodução & $3 / 12$ & 25,0 & $9 / 12$ & 75,0 & \\
\hline Subsistência & $14 / 99$ & 14,1 & $85 / 99$ & 85,9 & \\
\hline \multicolumn{6}{|l|}{ Sistema de criação } \\
\hline Extensivo & $13 / 103$ & 12,6 & $90 / 103$ & 87,4 & \multirow{3}{*}{0,892} \\
\hline Semi-intensivo & $5 / 46$ & 10,9 & $41 / 46$ & 89,1 & \\
\hline Intensivo & $4 / 40$ & 10,0 & $36 / 40$ & 90,0 & \\
\hline \multicolumn{6}{|l|}{ Comercialização de animais } \\
\hline Sim & $13 / 96$ & 13,5 & $83 / 96$ & 86,5 & \multirow{2}{*}{0,811} \\
\hline Não & $12 / 93$ & 12,9 & $81 / 93$ & 87,1 & \\
\hline \multicolumn{6}{|l|}{ Principal atividade } \\
\hline Bovinocultura & $5 / 75$ & 6,7 & $70 / 75$ & 93,3 & \multirow{3}{*}{0,392} \\
\hline Ovinocaprinocultura & $3 / 55$ & 5,5 & $52 / 55$ & 94,5 & \\
\hline Agricultura & $7 / 59$ & 11,9 & $52 / 59$ & 88,1 & \\
\hline \multicolumn{6}{|l|}{ Tamanho do rebanho } \\
\hline $1-40$ & $8 / 99$ & 8,1 & $91 / 99$ & 91,9 & \multirow{2}{*}{$0,128^{*}$} \\
\hline$>40$ & $14 / 85$ & 16,5 & $71 / 85$ & 83,5 & \\
\hline \multicolumn{6}{|c|}{ Participação em exposição/feira } \\
\hline Sim & $7 / 41$ & 17,1 & $34 / 41$ & 82,9 & \multirow{2}{*}{0,970} \\
\hline Não & $23 / 146$ & 15,8 & $123 / 146$ & 84,2 & \\
\hline \multicolumn{6}{|l|}{ Vermifugação dos animais } \\
\hline Não Faz/Faz 1x Ano & $5 / 99$ & 5,1 & $94 / 99$ & 94,9 & \multirow{2}{*}{$0,006^{*}$} \\
\hline 2-4x/Ano & $17 / 89$ & 19,1 & $72 / 89$ & 80,9 & \\
\hline \multicolumn{6}{|c|}{ Contato com outras espécies de animais } \\
\hline Sim & $12 / 98$ & 12,2 & $86 / 98$ & 87,8 & \multirow{2}{*}{0,819} \\
\hline Não & $13 / 90$ & 14,4 & $77 / 90$ & 85,6 & \\
\hline \multicolumn{6}{|l|}{ Higiene das instalações } \\
\hline Não faz & $10 / 34$ & 29,4 & $24 / 34$ & 70,6 & \multirow{2}{*}{$0,002^{*}$} \\
\hline Faz & $12 / 144$ & 8,3 & $132 / 144$ & 91,7 & \\
\hline
\end{tabular}

* Variáveis selecionadas e oferecidas para a regressão logística.

\section{CONCLUSÃO}

Foram verificados animais reagentes para a LA em carneiros da mesorregião do Sertão paraibano.
Com base nos resultados da análise de fatores de risco, recomenda-se uma intensificação da higiene das instalações e um manejo adequado durante a vermifugação dos animais.

Tabela 4 - Fatores de risco para a LA em carneiros, em propriedades da mesorregião do Sertão, Estado da Paraíba, determinados por regressão logística múltipla.

\begin{tabular}{lccc}
\hline Fatores de risco & Odds ratio & IC 95\% & P \\
\hline Não realizar higiene das instalações & 5,51 & {$[2,01-15,13]$} & 0,001 \\
Vermífugar os animais 2-4x/ano & 4,44 & {$[1,47-16,01]$} & 0,005 \\
\hline
\end{tabular}

Teste de Hosmer e Lemeshow: $\chi^{2}=1,07 ; \mathrm{P}=0,78$. 


\section{REFERÊNCIAS}

ARAÚJO-LIMA, R.C. et al. Ocorrência de Culicoides furens (Diptera: Ceratopogonidae) no Município de Lagoa Seca, Paraíba. In: CONGRESSO BRASILEIRO DE MEDICINA VETERINÁRIA, 31., 2004, São Luís, MA. Anais ... São Luís: Sociedade Brasileira de Medicina Veterinária, 2004. 1 CD.

BRASIL. Instituto Brasileiro de Geografia e Estatística (IBGE). Sistema IBGE de Recuperação Automática - SIDRA. Pesquisa Pecuária Municipal, 2006. Capturado em 18 nov. 2007. Online. Disponível em: http://www.sidra.ibge.gov.br/ $\mathrm{bda} /$ tabela/listabl.asp? $\mathrm{c}=73 \& \mathrm{z}=\mathrm{t} \& \mathrm{o}=20$.

COSTA, J.R.R. Língua azul: produção e padronização de antígeno para prova de imunodifusão em gel de ágar e prevalência nas mesorregiões sudoeste e sudeste do estado do Rio Grande do Sul. 2000. 87f. Tese (Doutorado em Medicina Veterinária) - Curso de Pós-graduação em Ciência Animal, Universidade Federal de Minas Gerais.

COSTA, J.R.R. et al. Prevalência de anticorpos contra o vírus da Língua azul em bovinos e ovinos do sudoeste e sudeste do Rio Grande do Sul. Arquivo Brasileiro de Medicina Veterinária e Zootecnia, v.58, n.2, p.273-275, 2006.

DEAN, A.G. EpiInfo version 6: a word-processing, database, and statistic program for public health on IBMcompatible microcomputers. Atlanta: Center for Diseases Control and Prevention, 1994. 601p.

DOHOO, I.R. et al. An overview of techniques for dealing with large numbers of independent variables in epidemiologic studies. Preventive Veterinary Medicine, v.29, p.221-239, 1996.

GIBBS, E.P.; GREINNER, E.C. Bluetongue and epizootic hemorrhagic disease. In: MPNATH, T.P. The Arbovirus. Epidemiology and ecology. Boca Raton: CRC, 1988. p.39-70.
HOSMER, D.W.; LEMESHOW, S. Applied logistic regression. New York: John Wiley \& Sons, 2000. 375p.

LAENDER, J.O. Língua Azul em rebanhos de ovinos e caprinos em três mesorregiões de Minas Gerais: análise da evidência clínica e sorológica e identificação de Culicoides sp. 2002. 92f. Dissertação (Mestrado em Medicina Veterinária) - Curso de Pós-graduação em Medicina Veterinária, Universidade Federal de Minas Gerais.

LOBATO, Z.I.P. Língua Azul: a doença nos bovinos. Revista Brasileira de Reprodução Animal, v.23, n.4, p.515-523, 1999.

LUEDKE, A.J.; ANAKWENZE, E.I. Bluetongue virus in goats. American Journal of Veterinary Research, v.33, n.4, p.1739-1745, 1972.

OSBURN, B.I. Bluetongue virus. Veterinary Clinics of North America: Food Animal Practice, v.3, n.10, p.547-561, 1994.

PARSONSON, I.M. Overview of bluetongue infection of sheep. In: WALTON, T.E.; OSBURN, B.I. Bluetongue, African horse sickness and related Orbivirus. Boca Raton: CRC, 1992. p.444-451

SELLERS, R.F. Bluetongue and related diseases. In: GIBBS, E.P.J. Virus diseases of food animals: a world geography of epidemiology and control. London: Academic, 1981. V.2, p.567-583.

SILVA, F.J.F. Relatório sobre estudos de ocorrência de Língua Azul em São Paulo: relatório da comissão de estudos. Brasília: Ministério da Agricultura. Portaria Ministerial, 1978. N.150.

THRUSFIELD, M. Veterinary epidemiology. 2.ed. Cambridge: Blackwell Science, 1995. 479p.

ZAR, J.H. Biostatistical analysis. 4.ed. Upper Saddle River: Prentice Hall, 1999. 663p. 